Didáctica. Lengua y literatura

ISSN: 1130-0531

http://dx.doi.org/10.5209/DIDA.57142

\title{
Las actitudes de los adolescentes hacia la poesía, su didáctica y la educación emocional en la ESO
}

\author{
Raquel Zaldívar Sansuán ${ }^{1}$
}

Recibido: 13 de marzo de 2017 / Aceptado: 9 de junio de 2017

Resumen. Este artículo pretende dar voz al estudiante de la ESO para conocer cuáles son sus actitudes hacia la poesía y la educación emocional. Por ello, preguntamos directamente a los adolescentes sobre su experiencia poética y su desarrollo de las competencias emocionales en el instituto. Las opiniones que manifiestan sobre la poesía y su didáctica en Lengua castellana y literatura nos permiten observar carencias y proponer mejoras que establecen relaciones entre la educación emocional y la didáctica de la poesía.

Palabras clave: poesía; didáctica de la poesía; Lengua castellana y literatura; educación emocional.

\section{[en] Teenagers attitude toward poetry, their didactics and emotional education throughout high school}

\begin{abstract}
This article aims to give a voice to the student of ESO to know what are their attitudes toward poetry and emotional education. Therefore, we directly asked teens about his poetic experience and its development of emotional competencies at the Institute. Perceptions that manifest about poetry and its teaching in Spanish language and literature enable us to observe shortcomings and propose improvements that establish relations between emotional education and the didactics of poetry.
\end{abstract}

Key words: poetry; poetry didactics; Spanish language and literature; emotional education.

\section{[fr] Les attitudes des adolescents vers la poésie, sa didactique et l'éducation émotionnel dans l'ESO}

Résumé. Cet article vise à donner une voix à l'étudiant de 1'ESO pour connaître leur attitude envers la poésie et l'éducation émotionnelle. Par conséquent, on demande aux étudiants directement sur leur expérience poétique et le développement des compétences émotionnelles à l'école secondaire. Les opinions exprimées par les adolescents sur la poésie et sa didactique en "Langue espagnole et sa littérature" permettent d'observer des lacunes et proposer des améliorations qui établissent des relations entre éducation affective et l'enseignement de la poésie.

Mots-clés: poésie, didactique de poésie, Langue espagnole et sa littérature, éducation émotionnelle

Sumario: 1. Poesía y educación emocional en la ESO. 2. Diseño del estudio sobre las actitudes de los adolescentes hacia la poesía, su didáctica y la educación emocional en la ESO. 3. Análisis de las opi-

1 Departamento de Didáctica de la Lengua y la Literatura

Universidad Complutense de Madrid

Raquel.zaldivar.sansuan@gmail.com 
niones y actitudes de los estudiantes sobre la poesía, su didáctica y la educación emocional en la ESO. 3.1. Respecto al gusto y el rechazo a la poesía. 3.2. Respecto a la relación de la poesía con la vida. 3.3. Respecto al aprendizaje poético vivido en la asignatura de Lengua castellana y literatura. 3.4. Respecto a los poetas y textos poéticos que les gustan. 3.5. Respecto a la existencia de la educación emocional en sus centros. 4. Conclusiones. 5. Bibliografía.

Cómo citar: Zaldívar Sansuán, R. (2017). Las actitudes de los adolescentes hacia la poesía, su didáctica y la educación emocional en la ESO. Didáctica. Lengua y literatura, 29, 2017, 259-277.

\section{Poesía y educación emocional en la ESO}

Las encuestas realizadas a adolescentes sobre hábitos lectores y compra de libros no colocan a la poesía en buen lugar dentro de la lectura literaria. Predomina el gusto por la novela o el cuento más que por la poesía y el teatro (Molina Villaseñor, 2006; Latorre, 2007; Millán, 2008; Informe El sector del libro en España, 2016).

El lector de secundaria se concibe principalmente como un lector de narrativa. La caracterización del lector adolescente (Díaz Plaja Taboada, 2006; Jover, 2007; Grupo Lazarillo, 2008) revela que los jóvenes no leen poesía, pero la conocen a través de las letras de las canciones de la música que escuchan. Sin embargo, este contacto cotidiano con el género poético no es relacionado por ellos con la poesía que se enseña en Lengua castellana y literatura. Llorens (2008) se muestra más optimista en este aspecto y afirma la existencia de una conciencia poética que el adolescente utiliza en su vida al leer o escribir en formato digital o material. Esta conciencia poética resultará clave para la comprensión y el disfrute de la poesía en el aula.

Los libros y propuestas de didáctica de la poesía para la ESO (Medina Rivilla y otros, 1984; Jean, 1996; Gómez Martín, 2002; Herrerías, 2003; Cantero García, 2009; Moreno, 2012) consideran que en la didáctica de la poesía en las aulas predomina un modelo historicista, memorístico y teórico. Por ello promueven propuestas que fomentan el trabajo activo individual, la participación en clase a través de la conversación literaria, la vivencia de la experiencia poética, la vinculación de la poesía con la realidad, la relevancia de los aspectos temáticos, el fomento del conocimiento emocional y la importancia del docente investigador. Además, se promueve el recitado, la reflexión e interpretación de poemas y la escritura creativa, sin perder el ejercicio de las particularidades del género poético como la métrica o las figuras retóricas. Si tenemos en cuenta a estos autores, en la práctica se está desaprovechando la potencialidad educativa que la poesía representa en la adolescencia, así como la predisposición natural al disfrute poético y al desarrollo de la sensibilidad estética.

La poesía y su didáctica tienen una doble vinculación con la educación emocional. Por un lado, el contenido temático de la poesía permite explorar el mundo interior del ser humano y desarrollar la conciencia emocional del adolescente. Por otro lado, la construcción estética de la poesía produce emociones en el lector, las cuales fomentan el desarrollo de una sensibilidad artística que resulta clave para la lectura activa y placentera. Sanjuán (2013) realiza una gran aportación a la educación literaria al investigar sobre la dimensión emocional que posee, explora los vínculos que existen entre la enseñanza de la literatura y la práctica de la educación emocional. 
La investigación y la práctica educativa en España manifiestan un interés creciente por la educación emocional dentro de la educación integral del adolescente en la ESO (Bisquerra, 2015, 269), pero este auge tiene una matización difusa en el marco legislativo. El objetivo de la educación emocional es desarrollar las competencias emocionales, sin embargo, estas competencias no aparecen nombradas como tal en Las competencias clave para el aprendizaje permanente (2006). En este documento las competencias emocionales se conciben como transversales a las ocho competencias clave. Siguiendo este marco de referencia europeo no se legisla explícitamente sobre las competencias emocionales a nivel estatal en el Real Decreto 1105/2014, de 26 de diciembre, por el que se establece el currículo básico de la Educación secundaria obligatoria y del bachillerato, ni en la Comunidad de Madrid en el DECRETO 48/2015, de 14 de mayo, del Consejo de Gobierno, por el que se establece para la Comunidad de Madrid el currículo de la Educación Secundaria Obligatoria.

Las competencias emocionales aparecen en los contenidos y estándares curriculares de asignaturas como Educación física, Música, Plástica o Lengua castellana y literatura. Además, las competencias emocionales tienen especial importancia en tres de las ocho competencias clave: Comunicación en la lengua materna, Competencias sociales y cívicas y Conciencia y expresión culturales. Esta última tiene un valor fundamental en las relaciones de la poesía con la educación emocional, ya que se define como: "Apreciación de la importancia de la expresión creativa de ideas, experiencias y emociones a través de distintos medios, incluida la música, las artes escénicas, la literatura y las artes plásticas" (Comisión Europea, 2007, 12).

A nivel práctico no se puede saber a ciencia cierta en qué grado se está desarrollando la educación emocional en los institutos. La experiencia personal vivida induce a pensar que en los centros de secundaria todavía no se han planteado las potencialidades de la educación emocional como sí se plantean en los centros de primaria. Tanto el estado de la cuestión planteado como el acercamiento a tres centros públicos de Educación Secundaria de la Comunidad de Madrid, en calidad de docente de Lengua castellana y literatura, nos llevan a querer conocer la percepción que los adolescentes tienen sobre la poesía, su didáctica y la educación emocional.

\section{Diseño del estudio sobre las actitudes de los adolescentes hacia la poesía, su didáctica y la educación emocional en la ESO}

Con el objetivo de obtener información sobre las actitudes que muestran los alumnos hacia la poesía y su aprendizaje, así como sobre la educación emocional experimentada en sus centros de estudio, se ha optado por la etnografía educativa como opción metodológica. El diseño de la investigación es de tipo cualitativo-interpretativo. Los encuestados pertenecen a dos institutos públicos situados en el centro de Madrid, son de clase media, de procedencia española y su nivel académico es bueno. La finalidad del estudio es realizar un análisis descriptivo e interpretativo de las actitudes que tienen los participantes sobre la poesía y su didáctica. 
La recogida de información se realizó a través de un cuestionario que 122 participantes de diferentes clases y cursos de la ESO completaron en una hora de clase, durante el segundo trimestre del curso escolar 2015/2016. Se seleccionan los tres primeros cursos de la ESO para conocer las concepciones creadas durante el primer ciclo de esta etapa. A nivel curricular en Lengua castellana y literatura la poesía aparece desde la perspectiva de género en $1^{\circ}$ y $2^{\circ}$, mientras que en $3^{\circ}$ comienza la perspectiva historicista. Dado que los cuestionarios se completan a mitad del curso escolar nos sirven para conocer las actitudes creadas en la etapa donde se otorga más libertad al profesor de lengua para plantear la enseñanza de la poesía.

\begin{tabular}{|l|l|l|}
\hline CURSO & MUESTRA & LUGAR \\
\hline $1^{\circ}$ ESO & 42 participantes & I.E.S. Gran Capitán (Madrid) \\
\hline $2^{\circ}$ ESO & 54 participantes & I.E.S. Gran Capitán (Madrid) \\
\hline $3^{\circ}$ ESO & 26 participantes & I.E.S. Cervantes (Madrid) \\
\hline TOTAL & 122 participantes & Dirección de Área territorial Madrid Centro \\
\hline
\end{tabular}

Tabla 1. Distribución de la muestra por cursos e institutos

El instrumento de recogida de información que se utiliza es el cuestionario de tipo mixto organizado en un total de 5 preguntas que los participantes responden en el papel. Para el análisis de datos seguimos el proceso general del análisis de datos cualitativos (Rodríguez Gómez y otros, 1996, 206): reducción de datos, disposición y transformación de datos, y obtención y verificación de conclusiones. Hemos utilizado el proceso de construcción de categorías inductivo, ya que se ha partido de la información que aportan los participantes en sus respuestas para crear las categorías abstractas generales.

En la siguiente tabla se especifican tanto los presupuestos de partida que dirigen la investigación como los objetivos de la misma. Además, se incluyen las preguntas del cuestionario relacionadas con dichos presupuestos y objetivos.

\begin{tabular}{|c|c|c|}
\hline Presupuestos de partida & Objetivos de investigación & Preguntas del cuestionario \\
\hline \multicolumn{3}{|l|}{ Respecto a la poesía } \\
\hline $\begin{array}{l}\text { 1. Entre los adolescentes, } \\
\text { las actitudes negativas } \\
\text { ante la poesía son mayores } \\
\text { que las actitudes positivas. }\end{array}$ & $\begin{array}{l}\text { 1. Conocer las actitudes } \\
\text { hacia la poesía } \\
\text { 1. 1. Conocer el gusto o re- } \\
\text { chazo hacia la poesía y sus } \\
\text { motivos. } \\
\text { 1.2. Conocer las relacio- } \\
\text { nes que establecen entre su } \\
\text { realidad y la poesía }\end{array}$ & $\begin{array}{l}\text { 1. ¿Te gusta la poesía? } \\
\text { Sí/No ¿Por qué? } \\
\text { 2. ¿Con qué aspectos de tu } \\
\text { realidad relacionas la poesía? }\end{array}$ \\
\hline
\end{tabular}




\begin{tabular}{|c|c|c|}
\hline \multicolumn{3}{|c|}{ Respecto al aprendizaje poético } \\
\hline $\begin{array}{l}\text { 2. En la práctica de la asig- } \\
\text { natura de Lengua castella- } \\
\text { na y literatura predomina } \\
\text { una didáctica de la poesía } \\
\text { que destaca los aspectos } \\
\text { teóricos y memorísticos, y } \\
\text { deja de lado el desarrollo } \\
\text { de la competencia Con- } \\
\text { ciencia y expresión cultu- } \\
\text { rales. }\end{array}$ & $\begin{array}{l}\text { 2. Conocer las experiencias } \\
\text { de aprendizaje poético } \\
\text { 2.1. Conocer los apren- } \\
\text { dizajes sobre poesía que } \\
\text { consideran haber realizado } \\
\text { dentro de la asignatura de } \\
\text { Lengua castellana y litera- } \\
\text { tura. } \\
\text { 2.2. Conocer los poetas y } \\
\text { textos poéticos que apre- } \\
\text { cian. }\end{array}$ & $\begin{array}{l}\text { 3. ¿Qué has aprendido sobre } \\
\text { poesía en la asignatura Lengua } \\
\text { castellana y literatura? } \\
\text { 4. ¿Puedes recordar poemas, } \\
\text { libros de poemas o poetas que } \\
\text { hayas leído y te hayan gusta- } \\
\text { do? }\end{array}$ \\
\hline \multicolumn{3}{|c|}{ Respecto a la educación emocional } \\
\hline $\begin{array}{l}\text { 3. La ausencia de inten- } \\
\text { cionalidad didáctica por } \\
\text { parte de los centros y los } \\
\text { profesores por introducir } \\
\text { la educación emocional en } \\
\text { los institutos públicos de la } \\
\text { Comunidad de Madrid. }\end{array}$ & $\begin{array}{l}\text { 3. Conocer la percepción } \\
\text { sobre la educación emocio- } \\
\text { nal en su instituto. }\end{array}$ & $\begin{array}{l}\text { 5. ¿Consideras que el instituto } \\
\text { te enseña a conocer y gestionar } \\
\text { tus emociones? Sí/No ¿Por } \\
\text { qué? }\end{array}$ \\
\hline
\end{tabular}

Tabla 2. Presupuestos de partida, objetivos y preguntas de investigación

\section{Análisis de las actitudes de los estudiantes sobre la poesía, su didáctica y la educación emocional en la ESO}

\subsection{Respecto al gusto y el rechazo a la poesía}

Como se observa en el gráfico, el 52,5\% de los participantes manifiestan que sí les gusta la poesía -Sí- o que les gusta al menos en alguna ocasión -Depende-, frente al $47,5 \%$ de los participantes que manifiestan que no les gusta la poesía-No- o que les es indiferente -Nulo. Por lo tanto, el porcentaje del gusto por la poesía es mayor que el del rechazo, sin embargo, la negación del gusto es la opción que más aparece.

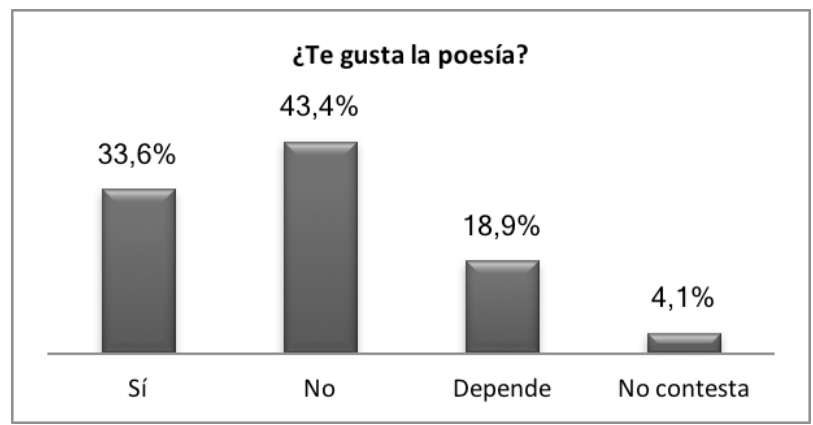

Figura 1. Resultados totales P.1. ¿Te gusta la poesía? 
Entre los motivos aportados por los participantes para justificar su gusto o rechazo seleccionamos una muestra que sirve para ejemplificar la variedad de sus argumentos.

\begin{tabular}{|c|c|}
\hline $\mathbb{N}$ & \\
\hline \multicolumn{2}{|r|}{$\begin{array}{l}\text { Is, sentimientos, gustos u opiniones" } 1^{\circ} \mathrm{ESO} \text {, } \\
\left.\text { tes" ( } 2^{\circ} \mathrm{ESO}, 1\right) \\
\text { mi mentalidad" }\left(2^{\circ} \mathrm{ESO}, 37\right) \\
\text { ocionalmente" }\left(2^{\circ} \mathrm{ESO}, 50\right) \\
\text { forma de recitarla" }\left(3^{\circ} \mathrm{ESO}, 15\right) \\
\text { ura general, te enseña cosas y te alivia" ( } 3^{\circ}\end{array}$} \\
\hline & \\
\hline \multicolumn{2}{|r|}{$\begin{array}{l}\text { tro la finalidad a la poesía. No entiendo lo } \\
\text { e en la vida. Me parece aburrida" ( } 2^{\circ} \mathrm{ESO} \text {, } \\
\text { unca ha sido algo que haya salido de mí, el } \\
\text { los profesores que me la han enseñado" ( } 2^{\circ} \\
\text { 8) } \\
\text { atención" }\left(3^{\circ} \mathrm{ESO}, 18\right)\end{array}$} \\
\hline & \\
\hline \multicolumn{2}{|c|}{$\begin{array}{l}\text { "Un poco, me gusta en parte porque mi padre me leía versos divertidos cuando era peque- } \\
\text { ña" }\left(1^{\circ} \mathrm{ESO}, 24\right) \\
\text { "Más o menos. A mí me encanta la poesía libre y los poemas que te transmiten y te llegan } \\
\text { al corazón. Odio los poemas antiguos con palabras extrañas" }\left(2^{\circ} \mathrm{ESO}, 23\right) \\
\text { "A veces igual alguna sí, las que reflejan cómo me siento" }\left(2^{\circ} \mathrm{ESO}, 38\right) \\
\text { "Depende de qué poema. Hay algunas que expresan mucho y cuentan historias muy boni- } \\
\text { tas. Pero otros poemas no me gustan y utilizan un lenguaje que no entiendo" }\left(3^{\circ} \mathrm{ESO}, 25\right)\end{array}$} \\
\hline
\end{tabular}

Tabla 3. Respuestas literales P.1. ¿Te gusta la poesía? ¿Por qué?

En general, los motivos que explican el gusto por la poesía son la valoración de la función estética del lenguaje poético, su consideración como forma de expresión del mundo mental y emocional, y la producción de bienestar. Los motivos que justifican el rechazo por la poesía son el no entendimiento, la carencia de sentido o utilidad y el aburrimiento. Además, aparecen argumentos en los que se compara negativamente con otros géneros literarios y formas de expresión. La función estética, que aparecía como motivo del gusto, es también nombrada como argumento para el rechazo de la poesía debido a la incomprensión que produce.

Los participantes que afirman que les agrada la poesía manifiestan un gran gusto por ella, aportando gran variedad de motivos. Este gusto proviene de experiencias 
positivas de vivencia poética, de vínculos afectivos relacionados con ello y de la consideración de un entendimiento que permite el disfrute.

Entre los motivos del aprecio a la poesía aparece una gran cantidad de producción y promoción de emociones, frente a los motivos del no que solo nombran el aburrimiento. Este no provoca cambio de emociones y si no se produce motivación aparece el hastío. El no haber sentido nunca la emoción estética así como la falta de estímulo de la no comprensión conllevan esta sensación. La búsqueda del contenido en el poema provoca una frustración si este no se encuentra. La incomprensión de lo comunicado y la ausencia de identificación conllevan un alejamiento por la falta de reconocimiento en la poesía.

Parte de las personas que repelen la poesía lo hacen por la comparación con la narrativa, género con el que están familiarizados. Buscan aplicar las mismas fórmulas para su comprensión, obviando la relevancia de la forma artística en la poesía. Estas personas desprecian la poesía por intentar obtener el significado del mensaje de la misma manera que se realiza en la prosa o en el lenguaje cotidiano. Todo esto nos lleva a pensar que las personas a las que no les gusta la poesía pueden recorrer en la asignatura de Lengua y literatura el camino hacia el disfrute poético.

\subsection{Respecto a la relación de la poesía con la vida}

En respuesta a la pregunta ¿Con qué aspectos de tu realidad relacionas la poesía? destacamos que 44 de los 122 participantes no relacionan la poesía con ningún aspecto de su realidad. El resto de participantes aportan un total de 93 respuestas que se agrupan en las categorías que observamos en el siguiente gráfico.

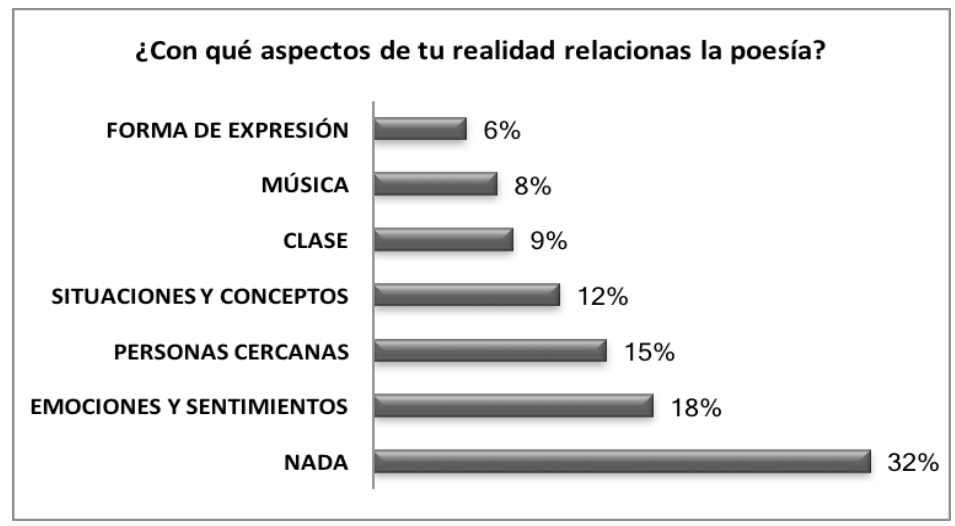

Figura 2. Resultados totales P.2. ¿Con qué aspectos de tu realidad relacionas la poesía?

En la siguiente tabla podemos observar respuestas textuales de los participantes a esta pregunta. 


\section{¿CON QUÉ ASPECTOS DE TU REALIDAD RELACIONAS LA POESÍA? \\ 1. CON EMOCIONES Y SENTIMIENTOS}

"Con mis sentimientos" ( $\left.1^{\circ} \mathrm{ESO}, 22\right)$

"Con el amor, la tristeza y el sentirse solo, la soledad" $\left(2^{\circ} \mathrm{ESO}, 11\right)$

"Con el aburrimiento" ( $2^{\circ}$ ESO, 12)

"Con el amor entre mi familia y amigos. La poesía la suelo relacionar con momentos alegres" (2० ESO, 23)

"La verdad que a veces leo poesía en portugués y mis problemas emocionales o deseos sentimentales futuros los canalizo un poco en esta forma" $\left(3^{\circ} \mathrm{ESO}, 20\right)$

\section{CON PERSONAS CERCANAS}

"A mi abuelo porque escribe poesías muy bonitas" (1 ESO, 3)

"Cuando alguien de mi familia, normalmente mi hermano, se pone a hablar en verso en medio de una comida" ( $\left.2^{\circ} \mathrm{ESO}, 20\right)$

"Con mi pareja, le he hecho uno o dos poemas de amor" (2 ESO, 26)

"La poesía la relaciono bastante con mi madre. Ella escribió un libro de poemas que desde pequeña me ha fascinado. La relaciono digamos que con el vínculo que tenemos ambas" $\left(3^{\circ} \mathrm{ESO}, 1\right)$

\section{CON SITUACIONES O CONCEPTOS}

"Cuando me quedo pensando en algo cerca de algún lugar bonito" $\left(1^{\circ} \mathrm{ESO}, 11\right)$

"Con la libertad" (1 $\left.{ }^{\circ} \mathrm{ESO}, 42\right)$

"Con la vida y la muerte" $\left(2^{\circ} \mathrm{ESO}, 16\right)$

\section{CON CLASE}

"Con mi profesora particular de francés, porque es cuando leo poesía. Siempre francesa" $\left(1^{\circ} \mathrm{ESO}, 13\right)$

"Con las clases de lengua y el instituto" $\left(2^{\circ} \mathrm{ESO}, 42\right)$

"Con la clase de lengua, solamente" $\left(3^{\circ} \mathrm{ESO}, 8\right)$

\section{CON LA MÚSICA}

"Cuando escucho música, el rap" (2 ESO, 25)

"A la mayoría de personas nos gusta la música. Al escuchar música escuchamos poesía" $\left(2^{\circ} \mathrm{ESO}, 31\right)$

"No escucho mucha poesía, pero todas las canciones tienen un lado poético, y escucho muchísima música" ( $3^{\circ}$ ESO, 25)

\section{CON UNA FORMA DE EXPRESIÓN}

"Cuando hablas y dices frases que riman me recuerdan a la poesía y cuando leo frases célebres y /o poéticas para fotos, estados..." $\left(2^{\circ} \mathrm{ESO}, 19\right)$

"Para mí la poesía en su mayor parte es rimar palabras, (aunque académicamente no sea eso), entonces cuando escucho por ejemplo a alguien rimar una palabra, pienso en la poesía" ( $\left.3^{\circ} \mathrm{ESO}, 18\right)$

Tabla 4. Respuestas literales P.2. ¿Con qué aspectos de tu realidad relacionas la poesía?

Entre los participantes que sí relacionan la poesía con su realidad se impone la vinculación con sentimientos o emociones nombrados como sustantivos abstractos 
"con el amor y la pena", seguida del vínculo con personas cercanas que disfrutan de la poesía y la han dado a conocer a los participantes. Esto nos lleva a considerar la importancia de la dimensión emocional y afectiva de la poesía en su relación con la vida, así como la importancia y significatividad del aprendizaje social. En tercer puesto aparece la evocación de situaciones y conceptos, es decir, la dimensión mental y contemplativa de la poesía.

A continuación, aparece la relación con clase de Lengua y literatura o con el instituto. Si tenemos en cuenta que todos los participantes han tratado la poesía como tema en la asignatura de Lengua castellana y literatura, podemos observar que la gran mayoría de ellos no consideran la clase como un aspecto de su realidad que les vincula con la poesía. Además, podemos considerar también la desconexión que existe entre su realidad y las clases.

La música es el penúltimo aspecto más nombrado, en las respuestas se manifiesta un reconocimiento de lo poético en las letras de las canciones. Concretamente es el rap el estilo musical que más aparece, lo cual puede tener que ver con la primacía de la letra sobre las bases musicales en este género, así como su asociación a la improvisación, a la rima callejera, y a la elaboración artística del lenguaje desde la oralidad. Por último, encontramos la consideración de la poesía como una forma de expresión artística peculiar, asimilada como tal en la vida de los participantes que la nombran.

Es necesario recordar que más de un tercio de los participantes no relaciona la poesía con ningún aspecto de su realidad, ni respecto al instituto ni respecto a la cultura. El vínculo de los que sí relacionan la poesía con su realidad personal se basa en: las emociones, sentimientos y pensamientos; la afectividad con personas cercanas que tienen relación con la poesía; la evocación de experiencias y de clases; la conexión con la música y otras formas de expresión artística

\subsection{Respecto al aprendizaje poético vivido en la asignatura de Lengua castellana y literatura}

En respuesta a la pregunta ¿Qué has aprendido sobre poesía en la asignatura Lengua castellana y literatura? destacamos que la gran mayoría de los participantes responde a la pregunta, aportan un total de 195 respuestas que se agrupan en las 7 categorías que aparecen a continuación.

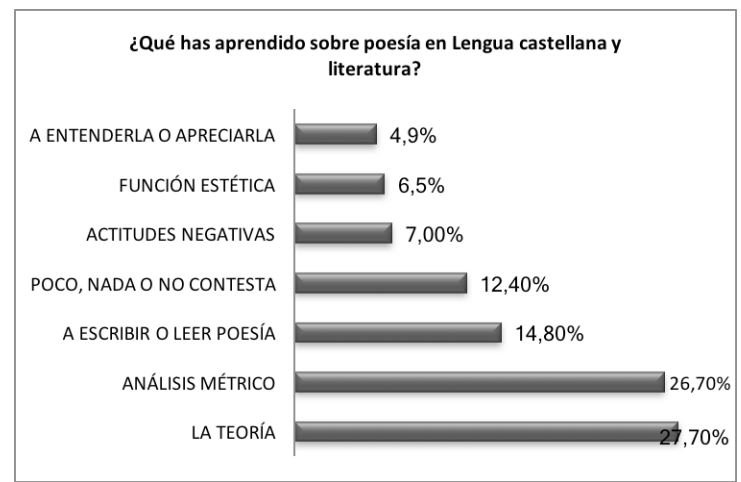

Figura 3. Resultados totales P.3. ¿Qué has aprendido sobre poesía en la asignatura de Lengua castellana y literatura? 
A continuación, mostramos una tabla en la que aparecen respuestas textuales que ilustran las relaciones que realizan los participantes.

¿QUÉ HAS APRENDIDO SOBRE POESÍA EN LA ASIGNATURA LENGUA CASTELLANA Y LITERATURA?

\section{LA TEORÍA}

"Un montón de términos literarios" ( $\left.1^{\circ} \mathrm{ESO}, 15\right)$

"La definición y algunos conceptos" $\left(1^{\circ} \mathrm{ESO}, 38\right)$

"Solo teoría no lo que significa ni el sentimiento del poema" $\left(2^{\circ} \mathrm{ESO}, 1\right)$

"Lo único que me han enseñado son las normas de la poesía" $\left(2^{\circ} \mathrm{ESO}, 54\right)$

\section{LA MÉTRICA}

"Cómo medir en sílabas un poema" ( $\left.1^{\circ} \mathrm{ESO}, 28\right)$

"Que se miden los versos, que puede tener rima asonante y consonante, que hay arte mayor o menor..." (2 $\left.{ }^{\circ} \mathrm{ESO}, 49\right)$

"He aprendido los tipos de rimas, también hemos aprendido a medir sílabas de un poema" $\left(3^{\circ} \mathrm{ESO}, 18\right)$

\section{A ESCRIBIR O LEER POESÍA}

"Hacer poesías" (1 ESO, 11)

"Cómo leerla" (1 ESO, 24)

"A poder escribir alguna, aunque fuera por obligación porque puede que si no me lo hubieran mandado escribir, no habría escrito ninguna" ( $\left.2^{\circ} \mathrm{ESO}, 9\right)$

\section{POCO, NADA O NO CONTESTA}

"Nada, en realidad, cuando hablábamos un poco de la poesía ha sido solo leer un poema y ni siquiera comentarlo" $\left(2^{\circ} \mathrm{ESO}, 5\right)$

"Poco, creo que he aprendido más por mí misma leyendo algún libro de poemas" $\left(2^{\circ} \mathrm{ESO}\right.$, 20)

"Poco, o al menos de los aspectos de la literatura relacionados con emociones" $\left(3^{\circ} \mathrm{ESO}, 8\right)$

\section{ACTITUDES NEGATIVAS HACIA LA POESÍA}

"Que es obligatoria en el aprendizaje" (2 $\left.2^{\circ} \mathrm{ESO}, 2\right)$

"Aprendido muchas cosas pero inútiles en mi día a día" $\left(2^{\circ} \mathrm{ESO}, 14\right)$

"Nada útil para mí, porque yo soy de ciencias" $\left(2^{\circ} \mathrm{ESO}, 19\right)$

\section{LA FUNCIÓN EMOTIVA Y ESTÉTICA DEL LENGUAJE POÉTICO}

"Que tiene que tener un lenguaje expresivo y emocionante" ( $\left.1^{\circ} \mathrm{ESO}, 21\right)$

"Que suele transmitir sentimientos o lo que piensa el poeta" $\left(1^{\circ} \mathrm{ESO}, 40\right)$

"Es una forma de embellecer el lenguaje, de una manera lírica" $\left(3^{\circ} \mathrm{ESO}, 25\right)$

\section{A ENTENDERLA O APRECIARLA}

"He aprendido a apreciarla" $\left(2^{\circ} \mathrm{ESO}, 3\right)$

"Me ha ayudado a conocerla mejor" $\left(2^{\circ} \mathrm{ESO}, 9\right)$

Tabla 5. Respuestas literales P.3. ¿Qué has aprendido sobre poesía en la asignatura Lengua castellana y literatura? 
En el aprendizaje poético manifestado por los alumnos se impone la teoría, seguida del análisis métrico. Ambas categorías suponen un 54,4\% de los ítems nombrados. En la teoría se incluyen referencias a la definición, las características, las figuras retóricas, la historia de la literatura y la teoría relativa a la métrica. En el análisis métrico incluimos respuestas que se refieren al proceso activo del análisis, para el que es necesario conocer la teoría.

La métrica en general es uno de los aspectos que más destaca por sí mismo: la medida de los versos, la rima y las estrofas parecen ser aspectos muy importantes en el aprendizaje poético. El verso como unidad y la rima y el ritmo como musicalidad son aspectos exclusivos del lenguaje poético. Su especificidad para el estudio del género puede explicar su relevancia en la enseñanza de la poesía.

La vivencia de la poesía -su escritura y lectura- aparece como el tercer aprendizaje más significativo, pero su importancia resulta escasa en la muestra, ya que solo aparece en un $14,8 \%$ de los ítems nombrados. Por lo tanto, se puede observar cómo el aprendizaje poético de los participantes está más orientado hacia la teoría poética que hacia la escritura creativa o el recitado de poemas. Además, la reducción de referencias a escribir o leer poesía de $1^{\circ}$ a $3^{\circ}$ de la ESO y las alusiones de los participantes de $1^{\circ}$ de la ESO a la educación primaria nos llevan a preguntarnos si se reduce la orientación a la vivencia del poema conforme avanzan los cursos.

Las dos categorías que muestran una percepción negativa hacia el aprendizaje poético en Lengua castellana y literatura aparecen en $4^{\circ}$ y $5^{\circ}$ lugar, sumando un $19,4 \%$ de los ítems totales. Por un lado, se considera un aprendizaje escaso o inexistente, y por otro se deja la respuesta en blanco. Estos casos manifiestan no haber aprendido sobre poesía. Por otro lado, aparecen actitudes negativas hacia la poesía que se han aprendido en clase y que conforman un prejuicio o dificultad en el acceso al disfrute poético. Principalmente son tres los motivos de la actitud negativa formada: complejidad del lenguaje poético, obligatoriedad o imposición, e inutilidad o carencia de sentido. Estos casos manifiestan haber aprendido una actitud negativa hacia la poesía en Lengua castellana y literatura.

En comparación a este rechazo encontramos las dos categorías que aparecen en menos ocasiones y que tienen que ver con una actitud positiva hacia la poesía aprendida en Lengua castellana y literatura. En 13 ocasiones los participantes se refieren a haber aprendido sobre las posibilidades de expresión de la poesía, como exteriorización de pensamientos y sentimientos o como ente estético y artístico. Es decir, destacan en su aprendizaje la función expresiva y estética del lenguaje poético, lo cual manifiesta un acercamiento adecuado a la poesía. Además, en 10 ocasiones aparecen referencias al entendimiento o apreciación de la poesía como aprendizaje desarrollado en clase, lo cual supone la formación de una opinión y una predisposición positiva. En total, las actitudes y percepciones positivas generadas en la asignatura suponen un $11,4 \%$ de las respuestas, porcentaje inferior a las actitudes negativas generadas en ella.

Si relacionamos los aprendizajes manifestados en Lengua y literatura con los vínculos de la poesía con la realidad de los participantes, atendemos a la siguiente reflexión. Los participantes ofrecen 137 ítems en relaciones de la poesía con la vida y su realidad, mientras que ofrecen 202 ítems en aprendizajes poéticos realizados en Lengua y literatura. Por la explicitación del número de ítems, los participantes encuentran más referencias al hablar de poesía en Lengua y literatura que de poesía en su vida. La poesía está más relacionada con las clases y la asignatura que con 
su realidad. Además, las diferencias entre las categorías de una y otra pregunta nos muestran una disociación entre su realidad y el instituto, se desliga la vida de la clase respecto a la poesía, y también, en general.

\subsection{Respecto a los poetas y textos poéticos que les gustan}

En respuesta a la pregunta ¿Puedes recordar poemas, libros de poemas o poetas que hayas leído y te hayan gustado? destacamos que casi la mitad de los participantes, un $45 \%$, no son capaces de nombrar ningún poeta o texto poético de su agrado. Lo cual resulta un porcentaje que manifiesta que el acercamiento a los poetas y textos poéticos no resulta muy relevante entre los participantes. "He leído pero no me gusta ninguno. Y los que he leído son en el instituto y son muy aburridos. Porque yo en mi casa no leo poesía" $\left(2^{\circ} \mathrm{ESO}, 12\right)$.

Como observamos en la tabla, entre los participantes que sí nombran se dan un total de 20 poetas en las 61 ocasiones en que aparecen nombres de poetas en las respuestas, 18 poemas diferentes en las 34 ocasiones en que se nombran poemas, y 10 libros de poemas en 21 apariciones de libros. La categoría de poetas es la que más variedad y cantidad de respuestas presenta, destacando su proporción respecto al resto de las categorías.

\begin{tabular}{|c|c|c|c|c|c|}
\hline \multicolumn{2}{|l|}{ POETAS } & \multicolumn{2}{|l|}{ POEMAS } & \multicolumn{2}{|l|}{ LIBROS DE POEMAS } \\
\hline $\begin{array}{l}\text { 1.Antonio Macha- } \\
\text { do }\end{array}$ & 11 & $\begin{array}{l}\text { 1."La canción del pirata" } \\
\text { José de Espronceda }\end{array}$ & 9 & $\begin{array}{l}\text { 1.La rosa de los vientos } \\
\text { (Antología poética) }\end{array}$ & 11 \\
\hline 2.Gloria Fuertes & 10 & $\begin{array}{l}\text { 2."El desayuno" Luis Al- } \\
\text { berto de Cuenca }\end{array}$ & 5 & $\begin{array}{l}\text { 2.Botella al mar } \\
\text { (Antología poética) }\end{array}$ & 2 \\
\hline $\begin{array}{l}\text { 3.Gustavo Adolfo } \\
\text { Bécquer }\end{array}$ & 7 & $\begin{array}{l}\text { 3."A Margarita Debayle" } \\
\text { Rubén Darío }\end{array}$ & 4 & 3.Rimas, Bécquer & 1 \\
\hline 4.Pablo Neruda & 7 & $\begin{array}{l}\text { 4."Caminante no hay ca- } \\
\text { mino..." Antonio Macha- } \\
\text { do }\end{array}$ & 2 & $\begin{array}{l}\text { 4.Platero y yo, Juan Ra- } \\
\text { món Jiménez }\end{array}$ & 1 \\
\hline 5.Rubén Darío & 4 & $\begin{array}{l}\text { 5. "Una rosa blanca" José } \\
\text { Martí }\end{array}$ & 1 & $\begin{array}{l}\text { 5.Las cuatro estaciones } \\
\text { (Antología poética) }\end{array}$ & 1 \\
\hline $\begin{array}{l}\text { 6.Juan Ramón Ji- } \\
\text { ménez }\end{array}$ & 4 & 6."Pato" Blas de Otero & 1 & $\begin{array}{l}\text { 6.Cuentos en verso para } \\
\text { niños perversos, Roald } \\
\text { Dahl }\end{array}$ & 1 \\
\hline 7.Loreto Sesma & 3 & $\begin{array}{l}\text { 7."El hada acaramelada" } \\
\text { Gloria Fuertes }\end{array}$ & 1 & $\begin{array}{l}\text { 7.La edad de oro, José } \\
\text { Martí }\end{array}$ & 1 \\
\hline $\begin{array}{l}\text { 8.Miguel Hernán- } \\
\text { dez }\end{array}$ & 2 & $\begin{array}{l}\text { 8."Elegía a Ramón Sijé" } \\
\text { Miguel Hernández }\end{array}$ & 1 & $\begin{array}{l}\text { 8. Las dos bandoleras, } \\
\text { Lope de Vega }\end{array}$ & 1 \\
\hline $\begin{array}{l}\text { 9.Federico García } \\
\text { Lorca }\end{array}$ & 2 & $\begin{array}{l}\text { 9."Soneto de repente" } \\
\text { Lope de Vega }\end{array}$ & 1 & $\begin{array}{l}\text { 9. Lo vívido vivido, Sharif } \\
\text { Fernández }\end{array}$ & 1 \\
\hline $\begin{array}{l}\text { 10.Mario Benede- } \\
\text { tti }\end{array}$ & 1 & $\begin{array}{l}\text { 10."La plaza tiene una to- } \\
\text { rre" Antonio Machado }\end{array}$ & 1 & $\begin{array}{l}\text { 10.Poesía anarquista li- } \\
\text { bre (blog) }\end{array}$ & 1 \\
\hline $\begin{array}{l}\text { 11.Luis Alberto de } \\
\text { Cuenca }\end{array}$ & 1 & $\begin{array}{l}\text { 11."Oda a la tristeza" Pa- } \\
\text { blo Neruda }\end{array}$ & 1 & & \\
\hline
\end{tabular}




\begin{tabular}{|c|c|c|c|c|c|}
\hline 12.Roald Dahl & 1 & $\begin{array}{l}\text { 12. "Volverán las oscuras } \\
\text { golondrinas..." Bécquer }\end{array}$ & 1 & & \\
\hline 13.Mónica Gae & 1 & $\begin{array}{l}\text { 13."Poema del mío Cid" } \\
\text { Anónimo }\end{array}$ & 1 & & \\
\hline $\begin{array}{l}\text { 14.Luis de Gón- } \\
\text { gora }\end{array}$ & 1 & $\begin{array}{l}\text { 14."Te espero" Mario Be- } \\
\text { nedetti }\end{array}$ & 1 & & \\
\hline 15.José Martí & 1 & $\begin{array}{l}\text { 15."A un olmo seco" An- } \\
\text { tonio Machado }\end{array}$ & 1 & & \\
\hline 16.Blas de Otero & 1 & $\begin{array}{l}\text { 16."Romance de la con- } \\
\text { desita" Anónimo }\end{array}$ & 1 & & \\
\hline 17. Oscar Wilde & 1 & $\begin{array}{l}\text { 17."À Aurore" George } \\
\text { Sand }\end{array}$ & 1 & & \\
\hline $\begin{array}{l}\text { 18.Sharif Fernán- } \\
\text { dez }\end{array}$ & 1 & $\begin{array}{l}\text { 18."Chanson d'automne" } \\
\text { Paul Verlaine }\end{array}$ & 1 & & \\
\hline 19.Suite Soprano & 1 & & & & \\
\hline 20. Kaze & 1 & & & & \\
\hline $\begin{array}{l}\text { TOTAL APARI- } \\
\text { CIONES } \\
\text { DE POETAS }\end{array}$ & 61 & $\begin{array}{l}\text { TOTAL APARICIONES } \\
\text { DE POEMAS }\end{array}$ & 34 & $\begin{array}{l}\text { TOTAL APARICIONES } \\
\text { LIBROS DE POEMAS }\end{array}$ & 21 \\
\hline
\end{tabular}

Tabla 6. Resultados de apariciones de poetas, poemas y libros de poemas

La inmensa mayoría de las respuestas que sí recuerdan poetas o textos poéticos de su agrado hacen referencia a poesía que forma parte del canon formativo de la asignatura de Lengua castellana y literatura, es decir, a la tradición poética. Tienen especial relevancia los poetas hispánicos y los poemas escritos originalmente en castellano. Casi todos ellos pertenecen a los últimos siglos de la tradición poética, el siglo XIX y $\mathrm{XX}$, apareciendo escasas referencias a la poesía medieval y a los Siglos de Oro.

"La canción del pirata" es el poema más nombrado, en 11 ocasiones. "Solo hay un poema que me gusta y no sé de quién es. Empieza con: con cien cañones por banda, viento en popa a toda vela..." $\left(2^{\circ} \mathrm{ESO}, 42\right)$. En todas las ocasiones se nombra "La canción del pirata" y no se nombra a su autor José de Espronceda. Para otros poemas, los participantes sí nombran al poeta que lo escribe pero esto no es lo habitual. "De Antonio Machado el poema de caminante no hay camino, se hace camino al andar..." (2 ESO, 2) o "Sí, Margarita Debayle de Rubén Darío, porque me regalaron el poema de pequeña y desde ahí es mi poema favorito" $\left(2^{\circ} \mathrm{ESO}, 3\right)$

La poesía está más relacionada con nombres de poetas y comienzos de poemas que con el libro y su título, por eso la categoría libros de poemas es la que menos apariciones tiene. Las antologías poéticas son utilizadas como material para la presentación de textos poéticos en clase, son el tipo de libro de poemas más nombrado. La rosa de los vientos es el libro de poemas más nombrado, se trata de una antología didáctica de poesía para el primer ciclo de ESO.

Los poemarios o poesías completas no se trabajan como material de difusión de la poesía, ni se leen, ni se utilizan en clase al mismo nivel que los libros de novela, sus iguales en el género narrativo. En el aprendizaje poético manifestado en Lengua y literatura se destacaba la teoría y el análisis métrico, no apareciendo citado ningún 
nombre de poeta o texto poético. Mientras que solo 25 personas afirmaban haber aprendido poco o nada, o no contestaban a la pregunta sobre el aprendizaje poético, 55 personas no nombran textos poéticos o poetas de su agrado. Esto nos lleva a preguntarnos si se enseña la poesía sin dar importancia a los textos poéticos en sí, ya que en el aprendizaje recordado por lo participantes la especificidad de género poético predomina sobre las manifestaciones del mismo.

La relevancia de la cultura poética, transmitida por el instituto o por la sociedad, que manifiestan los participantes nos lleva a pensar que no hay poesía fuera de lo que se reafirma por la institución educativa o cultural como poesía. "Leído no mucho, pero escuchado sí porque mi abuela recita poemas todo el rato, y al final me sé muchos de memoria de escucharlos. De Antonio Machado, de Miguel Hernández, de Rubén Darío... uno de los primeros que me aprendí fue el del olmo del Duero (no sé si se titula así) de Antonio Machado [...] Alguno que he leído ha sido de Gloria Fuertes" ( $2^{\circ}$ ESO, 53).

Los poetas o textos poéticos que están fuera de la institución, como los músicos, canciones o poetas actuales, tienen una representación prácticamente inexistente en la percepción de los participantes. La aparición de poetas o libros de poemas actuales es anecdótica, así como su vinculación con la música. "Me gusta una chica que se llama Loreto Sesma porque escribe poesía libre" $\left(2^{\circ} \mathrm{ESO}, 23\right)$. "Gloria Fuertes. Sharif: Cualquiera de sus temas y su libro: "Lo vívido vivido". Suite Soprano: cualquiera de sus temas. Kaze: cualquiera de sus temas" $\left(3^{\circ} \mathrm{ESO}, 26\right)$.

La otorgación del Premio Nobel de literatura en 2016 al cantautor Bob Dylan supone una admisión de las canciones como manifestaciones poéticas por parte de la institución literaria. Los casos de premios literarios a músicos son insignificantes, así como su aparición en la historia de la literatura. Nos lleva a preguntarnos si la institución crea el canon, o solamente admite una relación que ya realiza la sociedad. ¿El caso de Bob Dylan puede hacer que los participantes en el futuro nombren a músicos como poetas por la valoración de la letra de sus canciones?

\subsection{Respecto a la existencia de la educación emocional en sus centros}

Como se observa en la tabla, en respuesta a la pregunta ¿Consideras que el instituto te enseña a conocer y gestionar tus emociones? Si/No ¿Por qué? destacamos que la mayoría de los participantes, un $61,5 \%$, responde que el instituto no les enseña a conocer y gestionar sus emociones.

\section{$¿$ ¿Consideras que el instituto te enseña a conocer y gestionar tus emociones?}

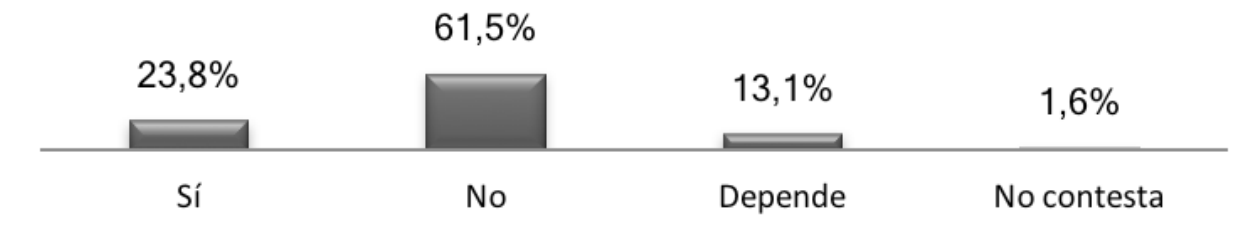

Figura 4. Resultados totales P.5. ¿Consideras que el instituto te enseña a conocer y gestionar tus emociones? 
Los motivos aportados por los participantes para justificar su respuesta se agrupan en las categorías que se especifican en la siguiente tabla, donde también se incluyen respuestas textuales de los participantes.

\begin{tabular}{|c|c|}
\hline \multicolumn{2}{|c|}{$\begin{array}{l}\text { ¿CONSIDERAS QUE EL INSTITUTO TE ENSEÑA A CONOCER Y GESTIONAR } \\
\text { TUS EMOCIONES? ¿POR QUÉ? }\end{array}$} \\
\hline \multirow[t]{8}{*}{ NO } & 1. AUSENCIA INTERÉS \\
\hline & $\begin{array}{l}\text { "Porque a ellos les damos igual, solo hacen su trabajo" }\left(1^{\circ} \mathrm{ESO}, 21\right) \\
\text { "Los profesores te sueltan la clase y se van, pasan más de ti que en el colegio y } \\
\text { no les importas nada" }\left(2^{\circ} \mathrm{ESO}, 13\right) \\
\text { "Porque aquí venimos supuestamente a estudiar y nuestras emociones a los } \\
\text { profesores no les importa" }\left(3^{\circ} \mathrm{ESO}, 20\right) \\
\text { "El sistema educativo vigente se centra en hacerte memorizar para después sol- } \\
\text { tarlo en un examen y olvidarlo según sales. Nunca nos han preguntado lo que } \\
\text { de verdad nos interesa" }\left(3^{\circ} \mathrm{ESO}, 26\right)\end{array}$ \\
\hline & 2. MÁS IMPORTANCIA ASIGNATURAS \\
\hline & $\begin{array}{l}\text { "Tristemente se centran más en la enseñanza de materias (lengua, mates...) que } \\
\text { en la enseñanza de uno mismo, es decir, de las personas, sus emociones, sus } \\
\text { maneras de pensar y todo lo que nos abarca" }\left(1^{\circ} \mathrm{ESO}, 16\right) \\
\text { "Para lo único que sirve es para atender a las clases y estudiar las asignaturas" } \\
\left(2^{\circ} \mathrm{ESO}, 2\right) \\
\text { "Solo me enseñan información sobre lengua, historia, música..." }\left(2^{\circ} \mathrm{ESO}, 27\right) \\
\text { "Se limitan a teorías, exámenes y poco más" }\left(3^{\circ} \mathrm{ESO}, 11\right)\end{array}$ \\
\hline & 3. IMPOSIBILIDAD DE SER TRATADO \\
\hline & $\begin{array}{l}\text { "Creo que es algo que se aprende solo" }\left(2^{\circ} \mathrm{ESO}, 15\right) \\
\text { "El instituto no me puede enseñar lo que sentir, eso se aprende diariamente, no } \\
\text { me puede enseñar lo que es amor hasta que yo lo experimente por mí misma" } \\
\left(2^{\circ} \mathrm{ESO}, 21\right) \\
\text { "Las emociones es una cosa que sale de ti y no te pueden enseñar en el insti- } \\
\text { tuto" }\left(3^{\circ} \mathrm{ESO}, 10\right) \\
\text { "Las emociones solo se aprenden de forma personal y se van construyendo a lo } \\
\text { largo de la vida" }\left(3^{\circ} \mathrm{ESO}, 14\right)\end{array}$ \\
\hline & 4. IMPOSICIÓN Y REPRESIÓN \\
\hline & $\begin{array}{l}\text { "Como mucho te enseñan a estresarte y a frustrarte con los exámenes" ( } 1^{\circ} \\
\text { ESO, } 10) \\
\text { "No te dejan ser libre, tienes que ser como un maniquí, quieto, atendiendo y } \\
\text { casi nunca te dejan expresarte" }\left(2^{\circ} \mathrm{ESO}, 48\right) \\
\text { "Porque en realidad no te dejan ser como tú eres ni expresar tus sentimientos" } \\
\left(3^{\circ} \mathrm{ESO}, 16\right)\end{array}$ \\
\hline
\end{tabular}




\begin{tabular}{|c|c|}
\hline \multirow[t]{6}{*}{ SÍ } & 1. VIVENCIA \\
\hline & $\begin{array}{l}\text { "Porque así puedes estar feliz aprobando, jugando o si suspendes estar triste" } \\
\left(1^{\circ} \mathrm{ESO}, 22\right) \\
\text { "Porque sueles tener tu primera relación, o segunda..." }\left(2^{\circ} \mathrm{ESO}, 6\right) \\
\text { "Porque hemos llorado, reído, peleado...con los amigos" }\left(2^{\circ} \mathrm{ESO}, 17\right)\end{array}$ \\
\hline & 2. INCLUSIÓN EN LO QUE TE ENSEÑAN \\
\hline & $\begin{array}{l}\text { "Nos enseñan respeto y educación" }\left(1^{\circ} \mathrm{ESO}, 19\right) \\
\text { "Te enseñan a no llorar, gritar o hacer otras cosas impulsivamente" }\left(2^{\circ} \mathrm{ESO}, 19\right) \\
\text { "No sé muy bien por qué pero mediante las asignaturas de algún modo u otro } \\
\text { nos lo transmiten }\left(3^{\circ} \mathrm{ESO}, 5\right)\end{array}$ \\
\hline & 3. INTERÉS \\
\hline & $\begin{array}{l}\text { "Porque a veces te preguntan cómo estás, qué te pasa, hacen cosas para saber } \\
\text { expresarlas..." }\left(1^{\circ} \mathrm{ESO}, 3\right) \\
\text { "Con los consejos que te dan puedes aclararte" }\left(3^{\circ} \mathrm{ESO}, 19\right)\end{array}$ \\
\hline $\begin{array}{l}\text { DE } \\
\text { PEN } \\
\text { DE }\end{array}$ & $\begin{array}{l}\text { "Algunos te enseñan a controlar tus emociones con juegos y ejercicios, otros } \\
\text { pasan de ti" }\left(1^{\circ} \mathrm{ESO}, 11\right) \\
\text { "Realmente tal cual no, creo que es algo que aprendimos en primaria, pero aquí } \\
\text { no le dan mucha importancia" }\left(1^{\circ} \mathrm{ESO}, 12\right) \\
\text { "No nos enseñan pero de alguna manera aprendemos a gestionarlas por ejem- } \\
\text { plo cuando nos regañan o algo parecido nos gustaría enfadarnos, responder, } \\
\text { gritar, pero no podemos y de esa manera aprendemos" }\left(3^{\circ} \mathrm{ESO}, 18\right)\end{array}$ \\
\hline
\end{tabular}

Tabla 7. Respuestas literales P.5.

¿Consideras que el instituto te enseña a conocer y gestionar tus emociones? ¿Por qué?

Entre los participantes que consideran que en sus centros no se enseña a conocer y gestionar sus emociones, la mayoría de ellos aporta motivos que hacen referencia a la falta de interés por parte de los profesores o del centro, o a una mayor importancia concedida a las asignaturas que a este tema. Por lo tanto, observamos que la educación emocional no se percibe por los participantes como un tema que el centro o los profesores conciban con interés propio.

Respecto a la imposibilidad del tratamiento didáctico de las emociones, los participantes sostienen que el conocimiento y la gestión emocional se aprenden con el propio hecho de vivir, no pueden ser enseñados directamente, sino que es necesaria una vivencia propia a través de la experiencia personal. Además, se apela a la imposibilidad misma de gestionar las emociones más allá de un conocimiento mayor o menor sobre ellas.

Los participantes que consideran conocer y gestionar sus emociones en el instituto manifiestan la relevancia de la experiencia propia respecto a la experiencia dirigida. Se observa en los participantes la importancia de la vivencia de emociones dentro del espacio social del centro. Las relaciones con la gente que se producen en el instituto y las emociones producidas por ello suponen la principal fuente de conocimiento y gestión emocional manifestada en los motivos del sí.

En muchas ocasiones se utilizan los mismos motivos para justificar la existencia de educación emocional y la ausencia de ella. Las normas y la adecuación a un 
ambiente común son consideradas como educación emocional para algunos participantes, mientras que esa misma formación es nombrada por otros como motivo para justificar la ausencia de educación emocional, puesto que lo asocian con una represión que impide la libre expresión de su yo. Lo que nos lleva a concluir la diferente apreciación de lo que es educación emocional entre los participantes. Se asocia la ausencia o presencia de educación emocional en sus centros con: el interés o desinterés del centro y los profesores hacia ellos o hacia el tema, con la vivencia personal, social o guiada, con la adecuación a unas normas, valorada como positiva o negativa y con la dificultad del tratamiento didáctico de las emociones.

\section{Conclusiones}

En el primer presupuesto de partida considerábamos que Entre los adolescentes, las actitudes negativas ante la poesía son mayores que las actitudes positivas. Pues bien, en la muestra analizada las actitudes negativas no son mayores que las actitudes positivas, sino que son ligeramente menores. En primer lugar porque poco más de la mitad de los participantes afirman que les gusta. En segundo lugar porque poco más de la mitad de los participantes relacionan la poesía con aspectos positivos de su realidad. Por lo tanto, observamos que las actitudes positivas aparecen más que las actitudes negativas pero aun así las actitudes negativas son abundantes, ya aparecen en casi la mitad de los participantes.

Respecto al segundo presupuesto de investigación que dice que En la práctica de la asignatura de Lengua castellana y literatura predomina una didáctica de la poesía que destaca los aspectos teóricos y memorísticos, y deja de lado el desarrollo de la competencia Conciencia y expresión culturales. Pues bien, en la muestra analizada se confirma este presupuesto. En primer lugar porque entre los participantes predominan mayoritariamente los aprendizajes teóricos y memorísticos sobre poesía, siendo minoritarias las prácticas que desarrollan la competencia Conciencia y expresión culturales. Además, casi la mitad de los participantes no recuerdan poetas o textos poéticos de su agrado, por lo que se observa un tratamiento ineficiente de los textos que resulta insignificante para el recuerdo.

En relación al tercer presupuesto de investigación que consideraba la ausencia de intencionalidad didáctica por parte de los centros y los profesores por introducir la educación emocional en los institutos públicos de la Comunidad de Madrid. Entre los participantes predomina la consideración de la ausencia de intencionalidad didáctica por desarrollar la educación emocional en sus centros. Los participantes consideran mayoritariamente que sus centros no enseñan a gestionar y conocer sus emociones. Por lo tanto, el tercer presupuesto de investigación se confirma en la muestra analizada.

A la hora de una formación integral la didáctica de la poesía no solo conlleva un aprendizaje cognitivo, sino también un aprendizaje vivencial, emocional y afectivo. Algunos de los aspectos que deberían potenciarse más en la asignatura de Lengua castellana y literatura son la escritura creativa, la lectura conjunta en el aula, la conversación literaria, las relaciones de la poesía con la música o la vinculación de la poesía con la realidad personal. El aprendizaje poético para que resulte vinculante debe ser experiencial. Así también, la gestión sobre las propias emociones solo pue- 
de llevarse de una manera satisfactoria si el implicado vivencia las emociones, no solo teoriza o habla sobre ellas.

Puede ser interesante la inclusión de formas de poesía no canónicas en las prácticas escolares, aprovechar las letras de las canciones de la música que escuchan como recurso para educar emocionalmente y enseñar poesía. Lo más importante es asociar la lectura de la poesía con sensaciones positivas, principalmente, con la comprensión y el entretenimiento. El principal objetivo del profesor de lengua a la hora de enseñar poesía debe ser dejar de lado el aburrimiento y la incomprensión, ya que estos son los principales motivos por los que se desprecia el género. Antes de pretender la memorización de la teoría sería necesario ofrecer una lectura poética variada y abierta, que muestre manifestaciones de todo tipo, las cuales sorprendan, llamen la atención de los adolescentes y provoquen cierta identificación o reconocimiento en el poema.

Concluimos que una didáctica de la poesía que quiera ser relevante en la vida de los participantes no puede pasar por alto la dimensión vivencial y emocional, que aparece mayoritariamente en las relaciones con su vida y minoritariamente en los aprendizajes poéticos realizados en la asignatura de Lengua castellana y literatura. La relevancia de las personas cercanas con las que relacionan la poesía en su vida y la importancia de la vivencia social como fuente de conocimiento y gestión emocional nos lleva a la consideración de la necesidad de fomentar el aprendizaje social y afectivo en la enseñanza de la poesía, fomentando los procesos comunicativos y la convivencia positiva en el aula.

\section{Bibliografía}

Bisquerra, Rafael y Pérez Escoda, Núria (2007): "Las competencias emocionales", UNED Educación XX1, 10, 61-82.

Bisquerra, Rafael, Pérez González, Juan Carlos, y García Navarro, Esther (2015): Inteligencia emocional en educación, Madrid, Síntesis.

Cantero García, Víctor (2009): "Los fantasmas del deseo en la poesía de Luis Cernuda o cómo potenciar la educación emocio-afectivo-sexual de los adolescentes en la ESO", Didáctica. Lengua y literatura, 21, 67-97.

Comisión Europea (2007): Competencias clave para el aprendizaje permanente en un marco de referencia europeo, Luxemburgo, Oficina de Publicaciones Oficiales de las Comunidades Europeas.

Decreto 48/2015, de 14 de mayo, del Consejo de Gobierno, por el que se establece para la Comunidad de Madrid el currículo de la Educación Secundaria Obligatoria.

Díaz-Plaja Taboada, Ana (2002): "El lector de secundaria", Aspectos Didácticos de Lengua y Literatura, 12, 171-195.

Gil Flores, Javier (2011): "Hábitos lectores y competencias básicas en el alumnado de educación secundaria obligatoria", UNED Educación XX1, 14 (1), 117-134.

Gómez Martín, Fernando (2002): Didáctica de la poesía en la educación secundaria, Madrid, Ministerio de Educación, Cultura y Deporte.

Observatorio de la Lectura y el Libro (2016): Informe El sector del libro en España, Ministerio de Educación, Cultura y Deporte.

Jean, Georges (1996): La poesía en la escuela. Hacia una escuela de la poesía, Madrid, Ediciones de la Torre. 
Jover, Guadalupe (2007): Un mundo por leer. Educación, adolescentes y literatura, Barcelona, Octaedro.

Lazarillo, Grupo (2006): "La caracterización del lector adolescente: una aproximación desde la objetividad y desde la subjetividad", $O C N O S, 2,93-103$.

Latorre Zacarés, Víctor (2007): "Hábitos de lectura y competencia literaria al final de la E.S.O”, OCNOS, 3, 55-76.

Llorens García, Ramón (2008): "La conciencia poética del lector adolescente, clave para la formación lectora", TABANQUE Revista Pedagógica, 21, 11-24.

López Herrerías, José Ángel (2003): Poesía y educación, Barcelona, Herder.

Medina Rivilla, Antonio, Escobar Ruescas, Julián, y Oliver Forner, Francisco (1984): Didáctica de la poesía. Antología poético-temática de autores españoles, Madrid, Edilibro.

Millán, José Antonio (coord.) (2008): La lectura en España Informe 2008. Leer para aprender, Madrid, Federación de Gremios de Editores de España.

Molina Villaseñor, Leandro (2006): "Lectura y educación: los hábitos lectores y su repercusión académica en Educación Secundaria Obligatoria”, OCNOS, 2,105-122.

Moreno, Víctor. (2012): Va de poesía, Pamplona, Pamiela.

Real Decreto 1105/2014, de 26 de diciembre, por el que se establece el currículo básico de la Educación Secundaria Obligatoria y del Bachillerato.

Rodríguez Gómez, Gregorio, Gil flores, Javier \& García jiménez, Eduardo (1996): Metodología de la investigación cualitativa, Granada, Ediciones Aljibe.

Sanjuán Álvarez, Marta (2013): La dimensión emocional en la educación literaria, Zaragoza, Prensas de la Universidad de Zaragoza. 